\title{
Allergic responses reduce the relaxant effect of $\beta$-agonists but not potassium channel openers in guinea-pig isolated trachea
}

\author{
S. Houjou*, K. lizuka*, K, Dobashi*, T. Nakazawa**
}

\begin{abstract}
Allergic responses reduce the relaxant effect of $\beta$-agonists but not potassium channel openers in guinea-pig isolated trachea. S. Houjou, K. Iizuka, K, Dobashi, T. Nakazawa. CERS Journals Ltd 1996.

ABSTRACT: This study was conducted to determine whether the relaxant effect of adenosine triphosphate (ATP)-sensitive potassium channel (KATP) openers on airway smooth muscle are reduced during the hyporesponsiveness of beta-adrenergic receptors.

Isometric tension was measured and dose-response curves were constructed for levcromakalim (a KATP opener), Y-26763 (another KATP opener), isoprenaline and theophylline in guinea-pig isolated trachea that was challenged with ovalbumin or pretreated in vitro with either isoprenaline or the KATP openers.

Antigen challenge in vitro significantly reduced the potency but not the efficacy of isoprenaline in tracheal strips from actively sensitized guinea-pigs. The concentration of drug that produced a half-maximum inhibition (IC50) was $0.014 \pm 0.004$ $\mu \mathrm{M}$ in the challenge group versus $0.006 \pm 0.001 \mu \mathrm{M}$ in the control group $(\mathrm{p}<0.05$; $n=9)$. The IC50 of levcromakalim $(1.73 \pm 0.17 \mu M ; n=6)$ and of theophylline $(110 \pm 3.1$ $\mu M$; $n=6$ ) were unaffected. Exposure to $4 \mu M$ isoprenaline for 30 min evoked betaadrenergic hyporesponsiveness: the IC50 of isoprenaline rose significantly from $0.010 \pm 0.001$ to $0.017 \pm 0.002 \mu \mathrm{M}(\mathrm{p}<0.01 ; n=6)$. No effect was observed on the relaxant actions of levcromakalim and theophylline. In contrast, prior incubation with either levcromakalim or $\mathrm{Y}-26763(300 \mu \mathrm{M}$ for $30 \mathrm{~min})$ significantly reduced the subsequent potency and efficacy of levcromakalim, but did not alter the effects of isoprenaline and theophylline.

We conclude that the relaxant effect of the adenosine triphosphate-sensitive potassium channel openers was independent of beta-adrenergic hyporesponsiveness in airway smooth muscle of guinea-pigs.

Eur Respir J., 1996, 9, 2050-2056.
\end{abstract}

*First Dept of Internal Medicine, and **College of Medical Care and Technology, School of Medicine, Gunma University, Gunma, Japan.

Correspondence: S. Houjou

First Dept of Internal Medicine

Gunma University School of Medicine

3-39-15 Showa-machi

Maebashi

Gunma

Japan 371

Keywords: adenosine triphosphate-sensitive potassium channel

beta-adrenergic hyporesponsiveness bronchial asthma

isoprenaline

theophylline

Received: September 191995

Accepted after revision June 301996
In the last $10 \mathrm{yrs}$ adenosine triphosphate (ATP)-sensitive potassium channel (KATP) openers, such as cromakalim, have been developed as antihypertensive agents [1-4]. These agents relax the smooth muscle of the airways as well as vascular smooth muscle [5] via membrane hyperpolarization [6-8], leading to the closure of the voltage-dependent $\mathrm{Ca}^{2+}$-channels [9], a decrease in agonist-induced inositol-1,4,5 triphosphate production [10], and a reduction in the contractile apparatus sensitivity to $\mathrm{Ca}^{2+}[11]$. Relaxation of airway smooth muscle occurs by KATP openers presumably mediated via a similar mechanism [12-14]. The deterioration of pulmonary function in asthmatics (morning dip) is prevented by the administration of levcromakalim [15], which is the active 3S, 4R enantiomer of cromakalim. This suggests that KATP openers may be useful in preventing asthma attacks. Indeed, levcromakalim relaxed the human bronchial smooth muscle in vitro $[16,17]$.

Although beta-adrenergic agonists are the most potent and widely-used bronchodilator agents, an allergic reaction and/or administration of a high dose of a betaadrenergic agonist reduces their relaxant effects due to a decreased number of beta-adrenergic receptors [18-21], and a dysfunction of signalling at postreceptor sites in bronchial asthma [22, 23]. Whilst the relaxant effects of beta-adrenergic agonists on the basal and developed tone of airway smooth muscle have been extensively investigated, it is not known whether an allergic reaction would reduce the spasmolytic effect of the KATP openers, and whether the administration of a high dose of a beta-adrenergic agonist would modulate the action of the KATP openers.

Accordingly, we evaluated the efficacy and potency of levcromakalim administered after antigen-induced contraction in vitro, and compared its effects with those of the conventional bronchodilators, isoprenaline (ISO) and theophylline (THEO). Finally, we evaluated the heterologous or homologous tachyphylaxis of the KATP openers using tracheal muscle treated with high concentrations of ISO, levcromakalim, or Y-26763 (a KATP opener) [24, 25]. 


\section{Materials and methods}

Active sensitization of guinea-pigs and assessment of passive cutaneous anaphylaxis (PCA) titre

Male Hartley guinea-pigs were actively sensitized with ovalbumin (OA), $1 \mathrm{mg} \cdot$ week $^{-1}$, i.p. $\times 4$, in $5 \mathrm{mg} \mathrm{Al}(\mathrm{OH})_{3}$. The $48 \mathrm{~h}$ PCA titre of the animals was more than 160 fold.

\section{Preparation of tracheal strip}

The trachea was removed from each animal anaesthetized with pentobarbitone sodium $\left(40 \mathrm{mg} \cdot \mathrm{kg}^{-1}\right.$ i.p. $)$ and dissected. The airways were first cut longitudinally at the centre of the cartilage opposite the smooth muscle, followed by slicing transversely into 10 strips approximately $3 \mathrm{~mm}$ wide. Strips were divided into two groups and tied with silk thread at the cartilage to minimize the difference in response to agonists due to the uneven distribution of receptors on the trachea. Thus, a pair of muscle chains consisting of five pieces of strips were obtained from one animal. Their contraction and relaxation characteristics were presumably identical. One chain was used for exposure to OA or drug treatment and the other served as control.

\section{Isometric measurement of tension development}

Strip chains were set between a hook and an isometric force transducer (strain gauge TB-612T, Nihon Kohden Ltd, Japan) connected to an amplifier (TB-611-T, Nihon Kohden Ltd, Tokyo, Japan) and a multipen recorder (R66, Rika Denki Ltd, Tokyo, Japan), and vertically mounted in a $10 \mathrm{~mL}$ Magnus tube filled with Tyrode's solution that was aerated continuously with $5 \% \mathrm{CO}_{2}$ in $\mathrm{O}_{2}$. The composition of the solution was: $\mathrm{NaCl} 136.8 \mathrm{mM}$; $\mathrm{KCl}$ $2.7 \mathrm{mM} ; \mathrm{CaCl}_{2} 1.8 \mathrm{mM} ; \mathrm{MgCl}_{2} 1 \mathrm{mM} ; \mathrm{NaH}_{2} \mathrm{PO}_{4} 0.4$ $\mathrm{mM}$; $\mathrm{NaHPO}_{3} 11.9 \mathrm{mM}$; glucose $5.6 \mathrm{mM}$; and temperature was kept at $37^{\circ} \mathrm{C}$. At the beginning of each experiment, tissues were subjected to a tension of $1.0 \mathrm{~g}$ and allowed to equilibrate for $60 \mathrm{~min}$. The solution was changed at 20 min intervals.

To obtain the maximal tension and to confirm stability of the preparations, the application of carbachol (100 $\mu \mathrm{M})$ with wash-out was repeated three times. The first carbachol-induced contraction was always small. The second and third contractions showed a comparable amplitude that exceeded the first contraction. Indomethacin (2 $\mu \mathrm{M})$, a cyclo-oxygenase inhibitor, was used throughout these experiments to prevent spontaneous tone development due to the release of cyclo-oxygenase products.

\section{Study design}

A pair of tracheal-strip chain preparations were contracted maximally by the addition of histamine (HIS), 3 $\mu \mathrm{M})$. The amplitude was approximately $60 \%$ of the maximal contraction evoked by carbachol $(100 \mu \mathrm{M})$. At the sustained phase of contraction induced by HIS, levcromakalim, ISO or THEO was cumulatively applied to the preparations to obtain dose-relaxant curves. After extensive washing with Tyrode's solution and a $1 \mathrm{~h}$ equilibration period, one tracheal segment was challenged with OA $\left(0.1 \mathrm{mg} \cdot \mathrm{mL}^{-1}\right)$ to initiate anaphylactic reaction (anaphylactic challenge group) for $60 \mathrm{~min}$, whereas the other tracheal segment was challenged with HIS $(3 \mu \mathrm{M})$ (control group) for the same duration. Preliminary experiments showed that $0.1 \mathrm{mg} \cdot \mathrm{mL}^{-1}$ of $\mathrm{OA}$ produced the maximal response in which the peak amplitude was comparable to that of the maximal contraction induced by carbachol $(100 \mu \mathrm{M})$. After extensive washing and readjustment of the basal tone at $1.0 \mathrm{~g}$, the construction of dose-relaxant curves was repeated with the reagents against the HISinduced contraction. Thus, comparisons between groups were performed.

In the second series of experiments, strips were incubated with high concentrations of ISO $(4 \mu \mathrm{M})$, levcromakalim $(300 \mu \mathrm{M})$ or $\mathrm{Y}-26763(300 \mu \mathrm{M})$ for $30 \mathrm{~min}$, followed by washing with Tyrode's solution for $5 \mathrm{~min}$ three times. Subsequently, basal tone was readjusted at $1.0 \mathrm{~g}$, and HIS $(3 \mu \mathrm{M})$ was applied to the muscle, followed by construction of dose-relaxant curves for levcromakalim, ISO or THEO. Control strips were added to the vehicle (distilled water or dimethylsulphoxide (DMSO)) of the relaxant agents for $30 \mathrm{~min}$. Finally, ISO $(10 \mu \mathrm{M})$ was applied to smooth muscle to determine the full relaxation. The chemical structures of the KATP openers are illustrated in figure 1 .

\section{Reagents}

Levcromakalim: (-)6-cyano-3,4-dihydro-2, 2-dimethyltrans-4-(2-oxo-1-pyrrolidyl)-2H-1-6-benzopyran-3-ol was a gift from Smithkline Beecham Pharmaceuticals. ONO1078: 8-(p-(4-phenylbutyloxy)benzoyl)amino-2-(tetrazol5-yl)-4-oxo-4H-1-benzopyran was from ONO Yakuhin Co. Ltd. Y-26763: (-)-(3S, 4R)-4-(N-acetyl-N-hydroxyamino)-6-cyano-3,4-dihydro-2,2-dimethyl-2H-1-benzopyran-3-ol was from Japan Tabaco Inc. KATP openers were dissolved in DMSO and stored at a concentration of $10 \mathrm{mM}$ at $4^{\circ} \mathrm{C}$ in the dark. Prior to use, they were diluted with Tyrode's solution. Other reagents were dissolved with distilled water and immediately used in the experiments. Carbamylcholine chloride (carbachol), histamine chloride, theophylline and DMSO were purchased from Sigma Chemical Co., St Louis, Missouri, USA. Isoprenaline chloride was obtained from Nikken Chemicals Co. Ltd. The $\mathrm{KCl}, \mathrm{CaCl}_{2}, \mathrm{MgCl}_{2}, \mathrm{NaH}_{2} \mathrm{PO}_{4}, \mathrm{NaHCO}_{3}$, glucose and $\mathrm{OA}$, were all obtained from Kanto Chemical Co. Inc., Tokyo, Japan.<smiles>CC1(C)Oc2ccc(C#N)cc2[C@@H](N2CCCC2=O)[C@@H]1O</smiles>

Levcromakalim<smiles>CC(=O)N(O)[C@H]1c2cc(C#N)ccc2OC(C)(C)[C@@H]1O</smiles>

Y-26763
Fig. 1. - Chemical structures of adenosine triphosphate (ATP)-sensitive potassium channel openers. 


\section{Statistical method}

The response to the relaxant reagents was normalized to the range from the initial basal tone to the peak contraction with HIS $(3 \mu \mathrm{M})$, and expressed as mean \pm SEM. The concentration of drug required to produce the halfmaximum inhibition (IC50) value was obtained from individual dose-response curves of each strip. The negative logarithm of IC50 was used for statistical evaluation. Mann-Whitney U-test was used to evaluate differences. A p-value less than 0.05 were considered to be statistically significant.

\section{Results}

\section{Antigen challenge in vitro}

Challenge with OA rapidly produced a contraction that persisted for more than $60 \mathrm{~min}$. The preparation was washed at least three times, $30 \mathrm{~min}$ after initiation of the OA challenge. Because the tension in some strips did not return to baseline even after such extensive washing, a leukotriene C4/D4 antagonist, ONO-1078 (1 $\mu \mathrm{M})$, was added during the washing stage to allow the basal tension to be readjusted at $1.0 \mathrm{~g}$. Control preparation was run in parallel except for contraction evoked by HIS but not by OA for $60 \mathrm{~min}$. No tachyphylaxis to HIS $(3 \mu \mathrm{M})$ was observed in control experiments.

Although dose-response curves for ISO were shifted to the right after the $\mathrm{OA}$ challenge without altering the maximal response (fig. 2a), relaxant efficacy and potency of levcromakalim did not change (fig. 2b). Since the maximal relaxation induced by ISO, levcromakalim and THEO were unchanged, only the IC50 values are summarized in table 1. The IC50 of levcromakalim and THEO were not affected by the OA provocation. Note that ISO was approximately 320 times more potent than levcromakalim,
Table 1. - IC50 values for the relaxant potency of isoprenaline, levcromakalim and theophylline after antigen challenge inactively sensitized guinea-pig trachea

\begin{tabular}{lccc}
\hline & & \multicolumn{2}{c}{ Antigen challenge } \\
\cline { 3 - 4 } Agent & & Control & OA \\
Isoprenaline & 9 & $0.006 \pm 0.001$ & $0.014 \pm 0.004^{*}$ \\
Levcromakalim & 6 & $1.94 \pm 0.43$ & $1.73 \pm 0.17$ \\
Theophylline & 6 & $110 \pm 2.1$ & $110 \pm 3.1$ \\
\hline
\end{tabular}

Values are expressed as mean \pm SEM. IC50: concentration of drug producing half-maximum inhibition; OA: ovalbumin $\left(1 \mathrm{mg} \cdot \mathrm{mL}^{-1}\right)$. *: significantly different from control values, $\mathrm{p}<0.05$. "Control" means data from time-matched experiments without OA challenge.

while THEO was 57 times less potent than levcromakalim. These results indicated that the relaxant action of levcromakalim was independent of the anaphylactic reaction in vitro, in contrast to the reduction of potency of ISO.

\section{Drug-induced desensitization}

Prior incubation with a high concentration of ISO, 4 $\mu \mathrm{M}$ for $30 \mathrm{~min}$, reduced the subsequent ISO relaxant potency and efficacy (fig. 3a). Neither the IC50 nor the maximal response of levcromakalim were affected by this treatment (fig. $3 \mathrm{~b}$ ). Table 2 summarizes the IC50 values.

By contrast, prior incubation with levcromakalim, 300 $\mu \mathrm{M}$ for $30 \mathrm{~min}$, markedly reduced its subsequent relaxant action (fig. 4a), but not the effects of ISO (fig 4b) and THEO (fig 4c). Pretreatment with another KATP opener, Y-26763, $300 \mu \mathrm{M}$ for $30 \mathrm{~min}$, also reduced its relaxant action (fig. 5a), but not the action of ISO and THEO (Fig. 5b and c).

Cross-tachyphylaxis between levcromakalim and Y26763 was observed in this study (fig. 6). Treatment with Y-26763 markedly reduced the effect of levcromakalim. a)

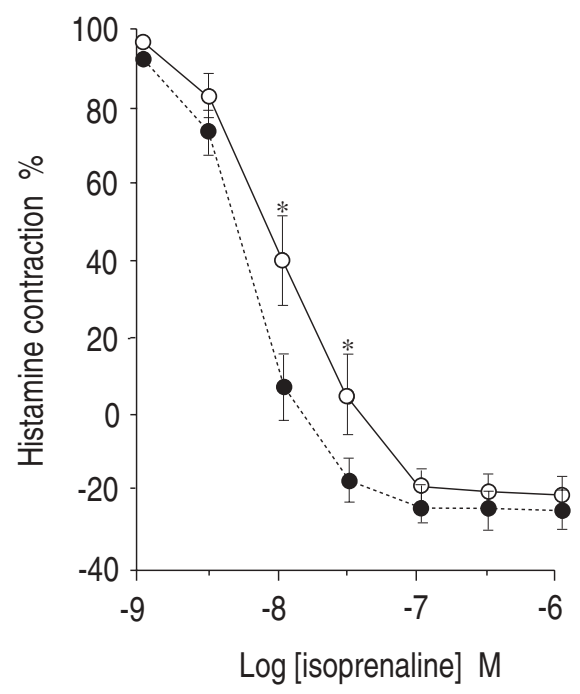

b)

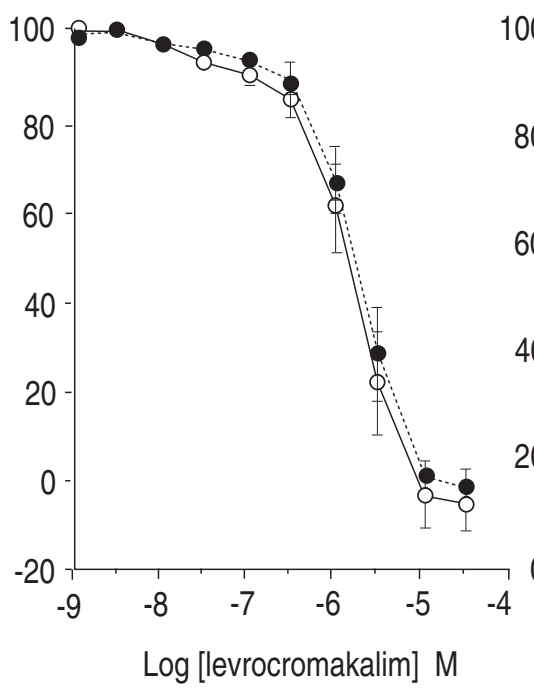

c)

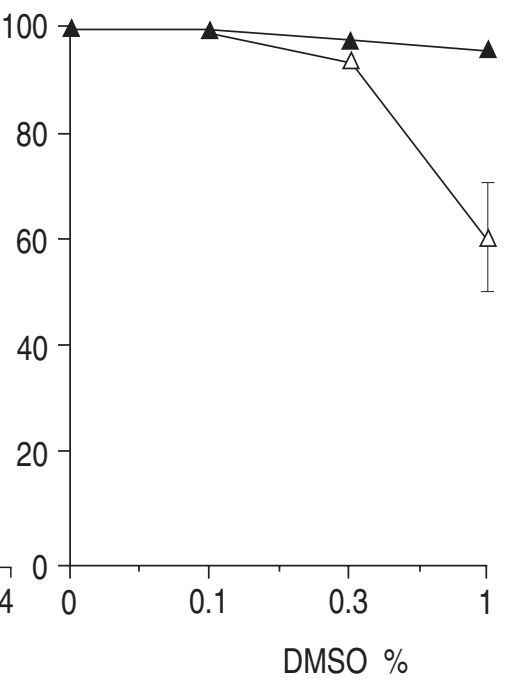

Fig. 2. - Reduction of relaxant potency of isoprenaline, but not of levcromakalim, by antigen challenge. The contraction induced by histamine $(3 \mu \mathrm{M})$ was relaxed by either: a) isoprenaline; b) levcromakalim, without $(\cdots \cdots)$ and with $(->-\cdots)$ antigen challenge (values are expressed as a percentage of initial histamine-induced contraction (mean \pm SEM) (n=6-9)); and c) relaxation of histamine $(\Delta)$ and carbachol $(\mathbf{\Delta})$ induced contraction by the dimethylsulphoxide (DMSO) used as solvent for levcromakalim ( $\mathrm{n}=3)$. *: p<0.05, significant difference (Mann Whitney U-test). 
a)

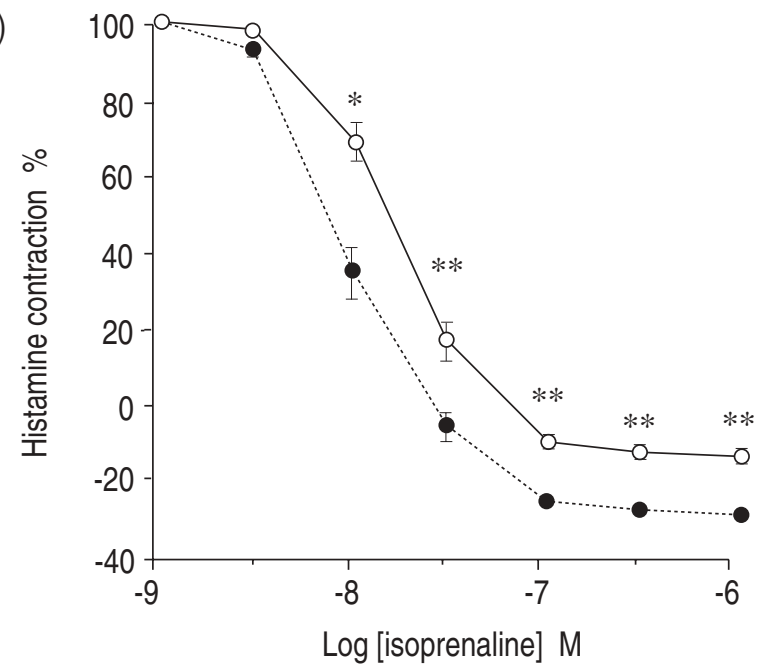

b)

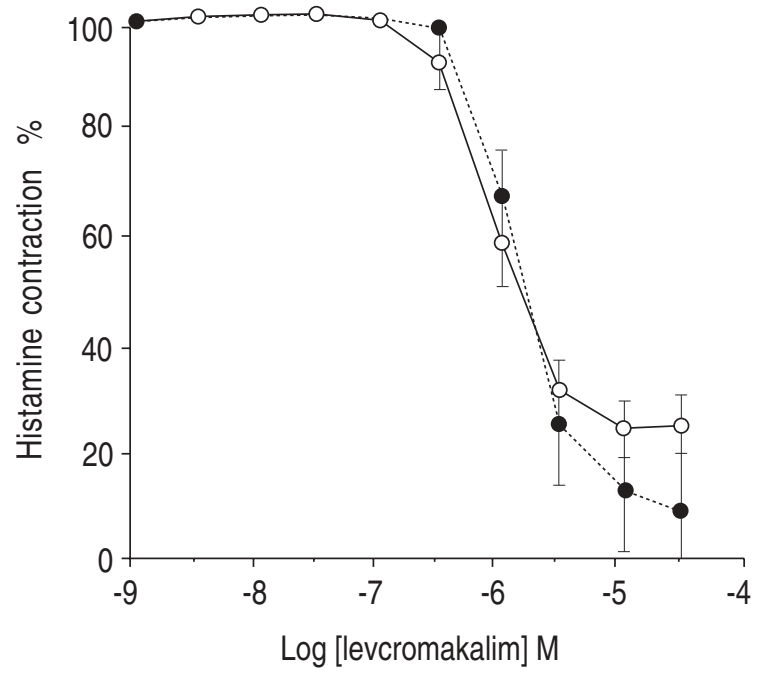

Fig. 3. - Tachyphylaxis of beta-adrenergic system in guinea-pig isolated trachea evoked by prior incubation with isoprenaline. Either: a) isoprenaline; or b) levcromakalim was cumulatively applied to the 3 $\mu \mathrm{M}$ histamine-contracted trachea without $(\cdots \bullet \cdots-\cdots)$ and with $(-\mathrm{O}-$ ) prior incubation with isoprenaline $(3 \mu \mathrm{M})$ for $30 \mathrm{~min}$. Values are expressed as a percentage of initial histamine-induced contraction $(\operatorname{mean} \pm \mathrm{sem})(\mathrm{n}=6) . *: \mathrm{p}<0.05 ; * *: \mathrm{p}<0.01$ vs without preincubation with isoprenaline (Mann Whitney U-test).

Table 2. - IC50 values for the relaxant potency of isoprenaline, levcromakalim and theophylline before and after incubation with isoprenaline $(4 \mu \mathrm{M})$ for $30 \mathrm{~min}$ in guineapig trachea

\begin{tabular}{lccc}
\hline & & \multicolumn{2}{c}{ Prior isoprenaline treatment } \\
\cline { 3 - 4 } Agent & & $(+)$ & $(-)$ \\
& $\mathrm{n}$ & $\mu \mathrm{M}$ & $\mu \mathrm{M}$ \\
\hline Isoprenaline & 6 & $0.017 \pm 0.002$ & $0.010 \pm 0.001^{* *}$ \\
Levcromakalim & 6 & $0.95 \pm 0.15$ & $1.28 \pm 0.33$ \\
Theophylline & 6 & $105 \pm 9.6$ & $120 \pm 8.0$ \\
\hline
\end{tabular}

Values are expressed as mean \pm SEM. IC50: concentration of drug producing half-maximum inhibition. $* *$ : significantly different from control values, $\mathrm{p}<0.01$
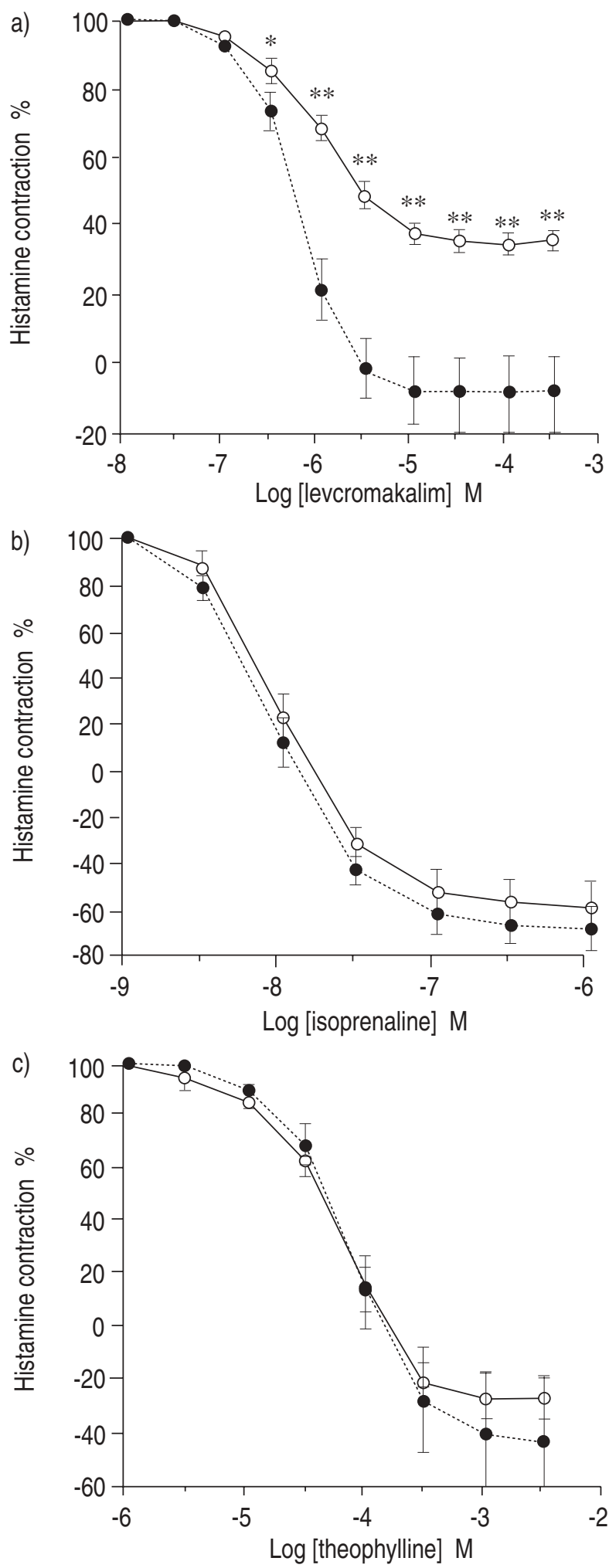

Fig. 4. - Tachyphylaxis of levcromakalim, but not of isoprenaline and theophylline, induced by prior incubation with levcromakalim. Levcromakalim, isoprenaline and theophylline were cumulatively applied to the $3 \mu \mathrm{M}$ histamine-contracted trachea without $(\cdots \cdots \cdots \cdots \cdots)$ and with $(-\mathrm{O}-)$ prior incubation with levcromakalim $(300 \mu \mathrm{M})$ for $30 \mathrm{~min}$. Values are expressed as a percentage of initial histamine-induced contraction (mean \pm SEM) $(\mathrm{n}=6) . *: \mathrm{p}<0.05 ; * * \mathrm{p}<0.01$, vs without preincubation with levcromakalim (Mann Whitney U-test). 

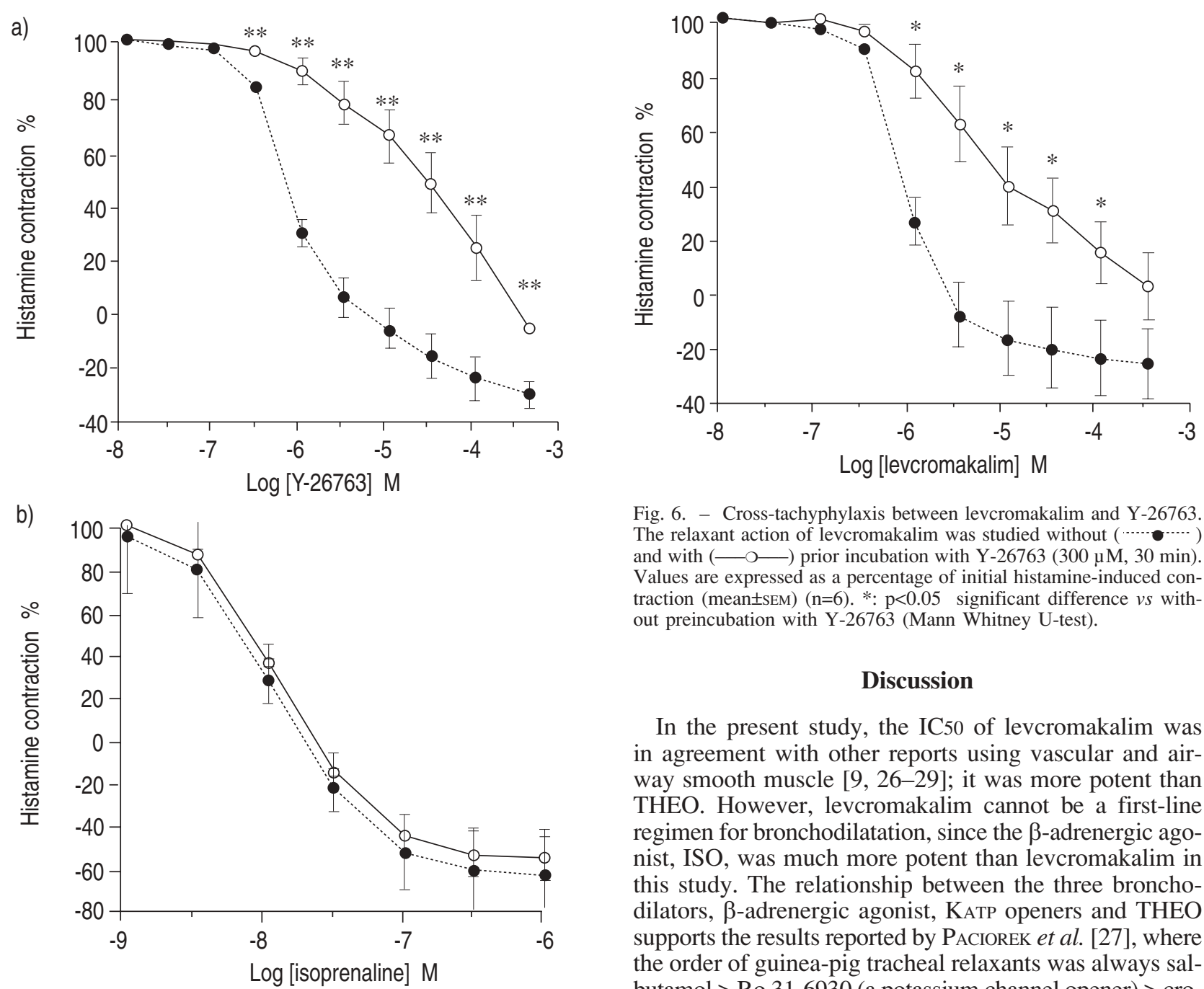

Fig. 6. - Cross-tachyphylaxis between levcromakalim and Y-26763. The relaxant action of levcromakalim was studied without (…….) and with (_- ) prior incubation with Y-26763 (300 $\mathrm{MM}, 30 \mathrm{~min})$. Values are expressed as a percentage of initial histamine-induced contraction $($ mean \pm SEM $)(n=6)$. *: $\mathrm{p}<0.05$ significant difference $v s$ without preincubation with Y-26763 (Mann Whitney U-test).

\section{Discussion}

In the present study, the IC50 of levcromakalim was in agreement with other reports using vascular and airway smooth muscle [9, 26-29]; it was more potent than THEO. However, levcromakalim cannot be a first-line regimen for bronchodilatation, since the $\beta$-adrenergic agonist, ISO, was much more potent than levcromakalim in this study. The relationship between the three bronchodilators, $\beta$-adrenergic agonist, KATP openers and THEO supports the results reported by PACIOREK et al. [27], where the order of guinea-pig tracheal relaxants was always salbutamol > Ro 31-6930 (a potassium channel opener) $>$ cromakalim > THEO.

Although levcromakalim was a more potent bronchodilator than THEO (about 57 times in this study), systemic application of the KATP openers brought some side-effects, such as headache, tachycardia and oedema [4]. Indeed, in patients with asthma, levcromakalim failed to show bronchodilator or protective effect against bronchoconstrictor challenge with HIS or methacholine at maximally tolerated systemic dose [30, 31]. Therefore, other drug delivery methods, such as inhalation, will be required to increase the concentration of levcromakalim up to a sufficient dose for bronchodilatation without systemic side-effects $[31,32]$. In this case, KатP openers may have a clinical advantage as a new bronchodilator, because their relaxant action was resistant to allergic response (fig. 2).

Either passively or actively (spontaneously) sensitized human bronchus revealed a decrease in relaxant efficacy of levcromakalim on basal tone through ion channel modulation [33]. In developed tone, however, the action of levcromakalim was not affected by sensitization itself [33], and by allergic response (this study). We observed that neither active nor passive sensitization influenced the relaxant effect of levcromakalim on HIS-induced contraction (data not shown). In addition to this, there was no cross-tachyphylaxis between ISO and levcromakalim 
or Y-26763 in guinea-pig tracheal muscle (figs. 4b and $5 b)$, whereas one-way cross-tachyphylaxis between salbutamol and levcromakalim was reported in rat uterus smooth muscle [34].

The effect of THEO was totally independent of antigen challenge (table 1) and of ISO- or KATP openerinduced tachyphylaxis (table 2 , and figs. $4 \mathrm{c}$ and $5 \mathrm{c}$ ). It is likely that tissue and species-related differences of KATP channels may exist [29]. Thus, levcromakalim may be suitable for additional treatment of severe asthma attack, such as "status asthmatics", when $\beta$-adrenergic agonist and THEO, even used in combination, do not reverse airway narrowing. Until airway inflammation and increased airway exudate are improved by anti-inflammatory drugs (e.g. corticosteroids), which usually requires several hours for relief, KATP openers may be beneficial to support the conventional bronchodilatation therapy.

Some loss of sensitivity to the KATP openers was observed following incubation with the openers at a high dose (figs. 4, 5 and 6). After the relaxant response to levcromakalim $(300 \mu \mathrm{M})$ had peaked, addition of Y$26763(300 \mu \mathrm{M})$ produced a small but significant additional relaxation (data not shown). However, this did not imply an additive effect of Y-26763, because the same dose of DMSO also decreased the tone further. It should be noted that DMSO itself (more than $1 \%$ ) relaxed the muscle (fig. 2c). Hence, we could not exclude the possibility that the effect of DMSO was involved in the relaxant action of the KATP openers at the high concentrations $(>30 \mu \mathrm{M})$ (figs. $2 \mathrm{~b}, 3 \mathrm{~b}, 4 \mathrm{a}, 5 \mathrm{a}$ and 6$)$.

The chemical structures of levcromakalim and Y-26763 are similar (fig. 1). However, there was a difference in the tachyphylaxis pattern between levcromakalim and Y26763. The tachyphylaxis induced by levcromakalim mainly decreased the efficacy of the drug (fig. 4a). In contrast, the treatment with Y-26763 caused a prominent reduction of potency rather than efficacy (fig. 5a). It is likely that this observation was not due to technical error, because similar rightward shifts of the dose-response curves for levcromakalim were obtained after the treatment with Y-26763 (fig. 6). Thus, the mechanisms of tachyphylaxis may be different between levcromakalim and Y-26763. Further studies are required to clarify this point. Nevertheless, these tachyphylaxis data suggest that physicians have to pay attention to desensitization. One needs to be aware of the possibility of desensitization in this class of compounds, especially when high doses of KATP openers are inhaled as a bronchodilators. Perhaps their use could be rotated with other conventional bronchodilators, such as $\beta$-adrenergic agonists and THEO.

In conclusion, the effect of levcromakalim on the histamine-induced contraction of isolated tracheal muscle was independent of $\beta$-adrenergic desensitization induced by allergic response and by the administration of a high dose of $\beta$-adrenergic agonist, although desensitization of adenosine triphosphate-sensitive potassium channels occurs by the adenosine triphosphate-sensitive potassium channel openers themselves. Additive studies are required for selective control of adenosine triphosphate-sensitive potassi-um channels on airway smooth muscle and for exploration of more airway specific potassium channel activators.

Acknowledgement: The authors thank M. Mori, of Gunma University School of Medicine, for excellent advice in preparation of this manuscript.

\section{References}

1. Vandenburg MJ, Woodward SR, Hossain M, StewartLong P, Tasker TCG. Potassium channel activators lower blood pressure: an initial study of BRL34915 in hypertensive patients. J Hypertension 1986; 4: S166-167.

2. Vandenburg MJ, Woodward SR, Stewart-Long P, et al. Potassium channel activators: antihypertensive activity and adverse effect profile of BRL34915. J Hypertension 1987; 5: S193-S195.

3. Cook NS. The pharmacology of potassium channels and their therapeutic potential. Trends Pharmacol Sci 1988; 9: 21-28.

4. Godfraind T, Govoni S. Recent advances in the pharmacology of $\mathrm{Ca}^{2+}$ and $\mathrm{K}^{+}$channels. Trends Pharmacol Sci 1995; 16: 1-4.

5. Small RC, Berry JL, Foster RW, Green KA, Murray MA. The pharmacology of potassium channel modulators in airway smooth muscle: relevance to airway disease. In: Weston AH, Hamilton TC, eds. Frontiers in Pharmacology and Therapeutics. Potassium Channel Modulators: Pharmacological, Molecular and Clinical Aspects. London. Blackwell Scientific Publications, 1993; pp. 422-461.

6. Longmore J, Weston AH. Effects of cromakalim and glibenclamide on isolated strips of bovine tracheal smooth muscle. Br J Pharmacol 1989; 98: 888.

7. Longmore J, Weston AH, Tresize D. The effects of cromakalim and diazoxide on potassium and rubidium permeability in bovine tracheal smooth muscle. Br J Pharmacol 1990; 183: 675.

8. Longmore J, Bray KM, Weston AH. The contribution of $\mathrm{Rb}$-permeable potassium channels to the relaxant and membrane hyperpolarizing actions of cromakalim, RP49356, and diazoxide in bovine tracheal smooth muscle. $\mathrm{Br} \mathrm{J}$ Pharmacol 1991; 102: 979-985.

9. Arch JRS, Buckle DR, Bumstead J, Clarke GD, Taylor JF, Taylor SG. Evaluation of the potassium channel activator cromakalim (BRL34915) as a bronchodilator in the guinea-pig: comparison with nifedipine. Br J Pharmacol 1988; 95: 763-770.

10. Yamagishi T, Yanagisawa T, Narita N. $\mathrm{K}^{+}$channel openers, cromakalim and Ki4032, inhibit agonist-induced $\mathrm{Ca}^{2+}$ release in canine coronary artery. Naunyn Sch Arch Pharmacol 1992; 346: 691-700.

11. Okada Y, Yanagisawa T, Taira N. BRL38227 (levcromakalim)-induced hyperpolarization reduces the sensitivity of $\mathrm{Ca}^{2+}$ of contractile elements in canine coronary artery. Naunyn Sch Arch Pharmacol 1993; 347: 438444.

12. Allen SL, Boyle JP, Cortijo J, Foster RW, Morgan GP, Small RC. Electrical and mechanical effects of BRL34915 in guinea-pig isolated trachealis. Br J Pharmacol 1986; 89: 395-405.

13. Berry JL, Elliott KRF, Foster RW, Green KA, Murray MA, Small RC. Mechanical, biochemical and electrophysiological studies of RP 49356 and cromakalim in guinea-pig and bovine trachealis muscle. Pulm Pharmacol 1991; 4: 91-98.

14. Murray MA, Boyle JP, Small RC. Cromakalim-induced relaxation of guinea-pig trachealis: antagonism by glibenclamide and phentolamine. Br J Pharmacol 1989; 98: 865-874.

15. Williams AJ, Lee TE, Cochrane GM, et al. Attenuation of nocturnal asthma by cromakalim. Lancet 1990; 336: 334-336.

16. Black JL, Armour CL, Johnson PR, Alouan LA, Barnes PJ. The action of a potassium channel activator, BRL38227 
(lemakalim), on human airway smooth muscle. Am Rev Respir Dis 1990; 142: 1384-1389.

17. Miura M, Belvisi MG, Stretton CD, Yacoub MH, Barnes PJ. Role of potassium channels in bronchodilator responses in human airway. Am Rev Respir Dis 1992; 146: 132-136.

18. Barnes PJ, Dollery CT, MacDermot J. Increased pulmonary $\alpha$-adrenergic and reduced $\beta$-adrenergic receptors in experimental asthma. Nature 1980; 285: 569-571.

19. Brooks SM, McGowan K, Bernstein IL, Alternau P, Peagler J. Relationship between number of beta-adrenergic receptors in lymphocytes and disease severity in asthma. J Allergy Clin Immunol 1979; 63: 401-406.

20. Conolly ME, Greenmacre JK. The lymphocyte $\beta$-adrenoceptor in normal subjects and patients with bronchial asthma. J Clin Invest 1976; 58: 1307-1316.

21. Kalisker A, Nelson HE, Middleton EJ. Drug-induced changes of adenylate cyclase activity in cells from asthmatic and nonasthmatic subjects. J Allergy Clin Immunol 1977; 60: 259-265.

22. Iizuka K, Yoshie Y, Nakazawa T. Hormone-sensitive adenylate cyclase in lymphocytes from asthmatic patients: possible defect at the postreceptor sites. Ann Allergy 1991; 66: 167-172.

23. Yukawa T, Makino S, Fukuda T, Kamikawa Y. Experimental model of anaphylaxis-induced beta-adrenergic blockade in the airways. Ann Allergy 1986; 57: 219-224.

24. Nakajima T, Shinohara T, Yaoka O, et al. Y-27152, a long-acting $\mathrm{K}^{+}$channel opener with less tachycardia: antihypertensive effects in hypertensive rats and dogs in conscious state. J Pharmacol Exp Ther 1992; 261: 730-736.

25. Itoh T, Ito S, Shafiq J, Suzuki H. Effects of a newly synthesized $\mathrm{K}^{+}$channel opener, Y-26763, on noradrenalineinduced $\mathrm{Ca}^{2+}$ mobilization in smooth muscle of rabbit mesenteric artery. Br J Pharmacol 1994; 111: 165-172.
26. Taylor SG, Bumstead J, Morris JEJ, Shaw DJ, Taylor JF. Cromakalim inhibits cholinergic-mediated responses in human isolated bronchioles but not in guinea-pig airways. Br J Pharmacol 1988; 95: 795P.

27. Paciorek PM, Cowlrick IS, Perkins RS, Taylor JC, Wilkinson GF, Waterfall JF. Evaluation of the bronchodilator properties of Ro 31-6930, a novel potassium channel opener, in the guinea-pig. Br J Pharmacol 1990; 100: 289-294.

28. Englert HC, Wirth K, Gehring D, et al. Airway pharmacology of the potassium channel opener, HOE 234, in guinea-pigs: in vitro and in vivo studies. Eur J Pharmacol 1992; 210: 69-75.

29. Kamei K, Yoshida S, Imagawa J, Nabata H, Kuriyama $\mathrm{H}$. Regional and species differences in glyburide-sensitive $\mathrm{K}^{+}$channels in airway smooth muscles as estimated from actions of KC 128 and levcromakalim. Br J Pharmacol 1994; 113: 889-897.

30. Kidney JC, Worsdell YM, Lavender EA, Chung KF, Barnes PJ. The effect of an ATP-dependent potassium channel activator, BRL38227, in asthmatics. Am Rev Respir Dis 1991; 143: A423.

31. Kidney JC, Fuller RW, Worsdell YM, Lavender EA, Chung KF, Barnes PJ. Effect of an oral potassium channel activator, BRL38227, on airway function and responsiveness in asthmatic patients: comparison with oral salbutamol. Thorax 1993; 48: 130-133.

32. Black JL, Barnes PJ. Potassium channels and airway function: new therapeutic prospects. Thorax 1990; 45: 213-218.

33. Villanove X, Marthan R, De Lara MA, et al. Sensitization decreases relaxation in human isolated airways. Am Rev Respir Dis 1993; 148: 107-112.

34. Downing SJ, Hollingsworth M. One-way cross tolerance between cromakalim and salbutamol in the uterus of the rat in vivo. Br J Pharmacol 1992; 105: 129-134. 